 \\ 1
}

\section{The Sharing Economy in Europe: From Idea to Reality}

\section{Cristina Miguel, Gabriela Avram, Andrzej Klimczuk, Bori Simonovits, Bálint Balázs, and Vida Česnuitytè}

\section{Introduction}

The 'collaborative economy' (or 'sharing economy,' as it is widely called) is best known for facilitating peer-to-peer exchanges through the means of digital platforms and mobile communication. As Gansky (2010) put it, the sharing economy is an idealised state characterised by the shift from ownership to renting, bartering, or gifting. Some authors argue for 'collaborative economies,' as this is an umbrella term incorporating many different stakeholder categories, business models, and forms of work,

C. Miguel ( $\varangle)$

Department of Applied IT, University of Gothenburg, Gothenburg, Sweden e-mail: cristina.miguel@ait.gu.se

G. Avram

University of Limerick, Limerick, Ireland e-mail: Gabriela.Avram@ul.ie

A. Klimczuk

SGH Warsaw School of Economics, Warsaw, Poland e-mail: aklimcz@sgh.waw.pl 
from Airbnb and Uber to urban gardening collectives and online patient communities. According to Avram et al. (2017), two groups of narratives stand out in relation to the collaborative economy, one focussing on social innovation and the aspiration to replace the current paradigm with more sustainable economic and environmental models that favour sharing access to goods and services, and a second, more widely spread one, that centres on the idea of market-focussed digital innovation able to disrupt existing business models and generate new economic activity.

The sharing economy has been described as a disruptive socioeconomic system that represents a major challenge to traditional economic models, which generally focus on hyper-consumption and private ownership (Botsman and Rogers 2010; Gansky 2010; Castells et al. 2012; Howard 2015). The sharing economy emerged around the financial crisis of 2007-2008 and related recession period. As Selloni (2017) pointed out, developments in technology and consumers seeking new ways to manage their finances in the context of the global economic downturn that followed the financial crisis came together and facilitated the nascent and emergent sharing economy. The sharing economy allowed cautious and financially constrained consumers to better manage their time, resources, budgets, and experiences. It also allowed those with resources to share and generate an additional and valuable income stream at a time when many incomes were either flat-lining or falling in real terms (Martos-Carrión and Miguel 2021).

The goal of this book is to provide readers with an original and comprehensive approach to the phenomenon of the sharing economy

\section{B. Simonovits}

Eötvös Loránd University, Budapest, Hungary

e-mail: simonovits.borbala@ppk.elte.hu

B. Balázs

Environmental Social Science Research Group, Budapest, Hungary

e-mail: balazs.balint@essrg.hu

V. Česnuitytè

Mykolas Romeris University, Vilnius, Lithuania

e-mail: v.cesnuityte@mruni.eu 
by covering themes around its conceptualisation, development, mapping across economic sectors, and country-specific case studies. This is an edited collection of chapters on the topic of the sharing economy that is still under discussion. Most of the authors of the chapters are participants in the COST Action CA16121 'From Sharing to Caring: Examining Socio-Technical Aspects of the Collaborative Economy' (abbreviated as 'Sharing and Caring'). The idea for the development of this book emerged as a consequence of the collaboration of researchers from numerous countries in this COST Action. This research network is funded by the European Cooperation in Science and Technology (COST) Association. The main objective of the Action is to develop a European network of actors focussing on the development of collaborative economy models and platforms and on social and technological implications of the collaborative economy through a practice-focussed approach. The 'Sharing and Caring' COST Action started in March 2017 and ended in September 2021. One of the initiatives of this research network was to collect and edit a series of country reports on the state of the art of the collaborative economy in the participating countries that could be useful for the COST Action participants and the general public. The first edition of the country reports collection was initiated in 2017 and published online in May 2018 (Mosconi et al. 2018). A second edition, initiated in 2019, was published on the Action website as an e-book in the autumn of 2021 (Klimczuk et al. 2021). This book builds on information originally included in the country reports. The first nine chapters include original research, further analysis, and synthesis. Also, seven country reports were selected and are expanded as thematic case studies in this edited collection. Therefore, the book was constructed in a way that makes it distinctive and unique in comparison to other publications related to the topic of the sharing economy.

\section{The Topic and Context}

The development of the sharing economy was fostered by the advance of new media technologies (e.g., Web 2.0, GPS) and the 2008 financial crisis (Martos-Carrión and Miguel 2021). Lawrence Lessig (2008) 
was probably the first author who used the term 'sharing economy' in his book Remix, where he defined the sharing economy in terms of the lack of interest in monetary gain to participate. Sharing economy activities may involve monetary exchange (e.g., Airbnb, BlaBlaCar, Car2go), or the exchange can be altruistic (e.g., CouchSurfing, OLIO, TimeBank). Nevertheless, sharing economy platforms mainly function as digital marketplaces where supply and demand are matched, either for economic compensation or for any other type of value exchange. Thus, rather than running in order to foster altruistic sharing, these new business models imply commodity exchange (Belk 2007). As Castells et al. (2012, p. 12) pointed out, the sharing economy is 'an alternative economy sector (not necessarily excluding for-profit production) based on a different set of values about the meaning of life.'

The sharing economy has also been described as the collaborative economy (e.g., Bauwens et al. 2012; Owyang et al. 2013) and collaborative consumption (e.g., Botsman and Rogers 2010; Germann Molz 2014; Hamari et al. 2016; Selloni 2017). According to Owyang et al. (2013, p. 4), 'the collaborative economy is an economic model where ownership and access are shared between corporations, start-ups, and people. This results in market efficiencies that bear new products, services and business growth.' Building on Botsman and Rogers (2010), Germann Molz (2014) explains that collaborative consumption is based on access rather than ownership and highlights the importance of digital platforms to facilitate the exchange of goods and experiences (e.g., ratings and reviews). In a similar vein, Hamari et al. (2016, p. 2047) argue that collaborative consumption is 'a peer-to-peer-based activity of obtaining, giving, or sharing access to goods and services, coordinated through community-based online services' where users can be providers, consumers, or both, the so-called 'prosumers' (Lang et al. 2020).

The fragmentation of the literature in a multitude of disciplines and research traditions most often leans back to one umbrella term, defined by Belk (2007) as 'an alternative to the private ownership that is emphasised in both marketplace exchange and gift-giving. In sharing, two or more people may enjoy the benefits (or costs) that flow from possessing a thing' (p. 127). To get to grips with the fragmentation, Frenken and Schor (2019) argued that the sharing economy has three 
defining characteristics: consumer-to-consumer interaction, temporary access, and physical goods. Earlier, Frenken et al. (2015) defined the sharing economy as 'consumers granting each other temporary access to under-utilised physical assets ('idle capacity'), possibly for money.' As for the multidimensionality of the term, Habibi et al. (2016) came up with the sharing economy continuum based on Belk (2007), ranging from pure sharing (see Belk's 2007 examples on that, e.g., mothering originally) to pure exchange (e.g., buying bread). While pure sharing can be labelled as non-reciprocal, personal and love and caring are key concepts. The pure exchange can be labelled as reciprocal, impersonal, and money is a key element (for more details, see Habibi et al. 2016, p. 4). Still, the depictions of the sharing economy remain rather contradictory and conceptually vague, especially in defining the purpose.

The main questions that the authors seek to answer in the book are the following:

1. How is the sharing economy understood nowadays? What are the social, business, and political aspects of this concept? What are the occurrences and interpretations of the sharing economy that can be observed in theory and practice?

2. What are the roles played by the sharing economy in the sharing and redistribution of goods and services across the population in order to maximise their functionality, monetary exchange, and other aspects important to societies?

3. What is the place of the sharing economy in connection to various policies? How do the contexts of public policies, legislation, digital platforms, and other infrastructure interrelate with the development and functioning of the sharing economy?

4. What are the contradictions in the development and recent trends in the sharing economy? Which sectors and characteristics of the sharing economy emerge as the most prominent in European countries?

5. What are the experiences and achievements in the sharing economy creation and practice that are characteristic to European countries? 
In terms of the scope of the analysis, the unique feature of our project is that our European perspective is based on local information and knowledge gathered through the multidisciplinary team of the COST Action's local researchers coming from 36 countries. However, it is important to note that we apply varied perspectives on a given topic, and our analysis is not comparative in a strict methodological sense. The timeframe of the analysis covers basically the past ten years, and we aim to assess the main trends, issues, and contradictions of the various sharing economy platforms operating since 2010. In geographic terms, we are focussing on the European countries that are members of our COST Action, namely, Albania, Austria, Belgium, Bosnia-Herzegovina, Bulgaria, Czech Republic, Croatia, Cyprus, Denmark, Estonia, Finland, France, Germany, Greece, Hungary, Ireland, Israel, Iceland, Italy, Lithuania, Luxembourg, Malta, Montenegro, the Netherlands, North Macedonia, Norway, Poland, Portugal, Romania, Spain, Slovenia, Slovakia, Sweden, Switzerland, Turkey, and the United Kingdom.

In essence, in this book, we record inherently contradictory tendencies in the sharing economy. From a critical social science point of view, our analysis demonstrates a shift in the motivational basis of the sharing economy. The sharing economy has been moving away from local and solidarity-based sharing, gifting, bartering, commoning (nonmarket-based ways of supply), and drifted easily towards commercialised and business-like activities. Under the auspices of 'sharing economy business model,' the market-logic has been introduced into ever new spheres of life and therefore-even if unintentionally-led to an extractivist, precarious society based on unsustainable practices, new inequalities, and extraction of human and natural resources (Belk 2014; Schor 2014; Bradley and Pargman 2017). Such inborn contradictions of the sharing economy are also illustrated by the growing differences and tensions in relations between users and providers of goods and services, the motivations for sharing between sectors, and socio-demographic dissimilarity within user groups (Böcker and Meelen 2017). As a main expectation towards the sharing economy, we contend that decoupling from growth could be a critical social promise of the sharing economy so that it could avoid being entirely insensible to socio-ecological problems. 


\section{Outline of the Book}

The content of the edited collection consists of eighteen chapters divided into three main parts (Parts II-IV) plus sections containing an Introduction (Part I) and a Conclusion (Part V). The Introduction is dedicated to familiarising the reader with the key topics and issues analysed in the book. The second part of the volume provides a discussion of the concept of the sharing economy as well as a secondary analysis of public policies, programmes, strategies, and legislative documents on the sharing economy. The third part analyses the sharing economy evolutionary practices in selected economic sectors such as mobility or accommodation, among others. The fourth part of this book includes case studies of selected European countries and is based on a selection of best practices, desk research, and the so-called 'short stories' collected within the framework of COST Action. Finally, the Conclusion includes the most significant features, achievements, and issues of the contemporary sharing economy in European countries and future-oriented observations, directions for further research, and recommendations. Each chapter contains an introduction, substantial sections, summary, references, suggested readings, and relevant websites, as well as the author's biographies.

In the first of the three main parts (Part II), the authors focus on the sharing economy conceptualisation, public policies and legislation, and developments that are led by discussions, contradictions, and tensions in European cities.

Chapter 2, authored by Cristina Miguel, Esther Martos-Carrión, and Mijalche Santa, takes up the challenge of conceptual clarification of the sharing economy term. The authors based their chapter on 20 top references, which included definitions of the sharing economy and identified the peculiar core properties of the sharing economy. Ten principles are abstracted: (P1) Redistribution of assets; access over ownership; (P2) The Internet and innovative technologies are the core of the sharing economy; (P3) The sharing economy is a market-based system; (P4) The sharing economy is crowd-based; (P5) The sharing economy is built on decentralised networks; (P6) The sharing economy enables peer-to-peer (P2P) transactions while empowering individuals; (P7) The sharing economy 
is a socio-economic system that disrupts traditional economic systems; (P8) Trust among strangers enhances social value. Trust is mostly based on reputation systems; (P9) Prosumers play an important role in peer production; and (10) The sharing economy emphasises collective experiences, co-creation, and sustainable lifestyles. Finally, Chapter 2 defines the sharing economy according to these principles.

In Chapter 3, Błażej Koczetkow and Andrzej Klimczuk analyse the sharing economy from a public policy perspective. Firstly, the text focuses the attention on the development of the sharing economy as a driver of both positive economic effects and public problems (e.g., labour market, traditional market sectors). Second, the chapter identifies possible actions for regulating different sharing economy activities. The chapter discusses the role of soft law, stakeholders' networks, self-regulation, and standardisation.

Kosjenka Dumančić and Natalia-Rozalia Avlona, in Chapter 4, address the legal definition of the sharing economy and consider problematic the lack of a general European Union legal framework for the sharing economy, apart from a European Commission Communication from 2016. The main objective of this chapter is to discuss the issues related to the lack of clear regulation of sharing economy activities at the EU level. The chapter analyses the contradictory regulations of some sharing economy activities in various European countries. The lack of harmonisation in the regulation of the sharing economy in different European countries is analysed within the framework of two case studies: Uber and Airbnb.

In the next main part of the volume (Part III), the authors cover analyses of sharing economy evolutionary practices in selected economic sectors: mobility and transportation, peer-to-peer accommodation, food supply chains, financial services, education, knowledge, and data sharing, as well as in the solidarity and care sectors.

In Chapter 5, Agnieszka Lukasiewicz, Anikó Bernát, and Vera Diogo analyse the main shared mobility services in Europe, such as car-based sharing models, bike-sharing, and electric scooter sharing. In particular, Chapter 5 provides a discussion of different car-based sharing models, which include: (1) car-sharing (e.g., public such as Car Sharing Rome, or private such as Share Now); (2) ride-hailing, which parallels taxi 
services (e.g., Uber), (3) ride-sharing (e.g., BlaBlaCar); and (4) carpooling, where associates and employees of individual companies can select a car from a fleet of vehicles as required. The chapter also examines conflicts in different European countries caused by shared mobility aspects and the possible effects of the COVID-19 pandemic.

Anna Farmaki and Cristina Miguel discuss the evolution of the peerto-peer (P2P) accommodation market sector in Europe in Chapter 6. First, the chapter distinguishes between free P2P accommodation platforms (e.g., CouchSurfing, BeWelcome); reciprocal P2P accommodation (e.g., HomeExchange, HomeSwap); and paid P2P accommodation platforms (e.g., Airbnb, HomeAway). The case study of Airbnb is introduced here to provide an overview of the platform's origins, evolution, and services. Later, the chapter provides an analysis of both opportunities and challenges that emerge from P2P accommodation activity's rapid growth. The chapter offers insights that may illuminate the understanding of the drivers, inhibitors, and influencers pertinent to the P2P accommodation market sector's development and resilience potential amid the COVID-19 pandemic.

In Chapter 7, Bori Simonovits and Bálint Balázs explore different aspects of the sharing economy within the food supply chains. The chapter offers an analysis of the topic with varied case examples at multiple value chain points (e.g., production, processing, transport, and consumption). Various peer-to-peer production and collaborative consumption initiatives are presented to assess how the idea of the sharing economy entered the food sector. The authors observe that in contrast to the accommodation and transport sectors, the food sector seemed to be probably the quickest-growing area of the sharing economy during the years 2020-2021. In particular, they address how the food delivery sector, the so-called uberisation of food (when contract workers use their personal vehicles to deliver food to customers), has gained even more momentum during the COVID-19 times.

Agnieszka Lukasiewicz and Mijalche Santa cover financial services and crowdfunding evolution within the sharing economy in Chapter 8 . Financial services in the sharing economy range from peer-to-peer lending to crowdfunding, with participation from new start-ups and incumbent financial service providers with for-profit or non-profit goals. 
The chapter covers different crowdfunding models, namely, donationbased, reward-based, equity-based, royalty-based, and lending-based financial services. It also addresses the value market of alternative financing and the impact of the COVID-19 pandemic in crowdfunding.

Gabriela Avram and Eglantina Hysa address the topics of open education, open design, knowledge, and data sharing in Chapter 9. First, the chapter explores the origins of online peer-to-peer collaborative learning, which can be found in the Open-Source Software movement and in the Wikipedia information production and consumption model. Next, the chapter presents and discusses examples of educational platforms, open education, and shared resources and initiatives in Europe. The text also discusses issues related to platforms facilitating collaborative information production and consumption.

In Chapter 10, Penny Travlou and Anikó Bernát describe the emergence of solidarity actions in two European countries-Greece and Hungary-in response to two recent crises: the arrival of large numbers of refugees in 2015 and the COVID-19 pandemic in 2020. The chapter discusses how the solidarity economy emerged during the 2008 financial crisis and how it was framed not only on monetised value but mostly on care and nurturing. The chapter is based on an ethnographic study that collected data via participant observation, interviews, and focus groups with grassroots solidarity collectives. Penny Travlou and Anikó Bernát embed the solidarity economy within the sharing economy, understood here as a new economic model that includes alternatives to the mainstream capitalist market.

In the third of the main parts of the book (Part IV), the authors' present case studies based on seven selected European country reports that cover best practices in some areas of the sharing economy. For example, the Netherlands case was selected for the country's pioneering initiatives in car-sharing, rental of vehicles, and bike-sharing services; France was selected for car-pooling practices, as well as its private chauffeur services; and the United Kingdom (UK) for its advanced initiatives and experience with time banks.

In Chapter 11, Martijn de Waal and Martijn Arets discuss shared mobility and gig work platforms in the Netherlands, which is one of the pioneer countries in the sharing economy. First, the chapter covers 
definitions and debates of the sharing economy in the Netherlands. The second part of the chapter focuses on the analysis of three forms of shared mobility that have been debated widely in the Netherlands: bike-sharing, car-sharing, and ride-hailing, covering some local initiatives as well as international players operating in the country, such as Uber. Finally, Chapter 11 critically analyses the gig economy in the Netherlands, which some see as an opportunity for economic growth, while others fear it would lead to the deterioration of workers' rights.

Myriam Lewkowicz and Jean-Pierre Cahier analyse the cooperative platform sector, as an alternative platform model in France, in Chapter 12. First, the chapter provides an overview of the French platform cooperativism ecosystem, highlighting why and how a number of platform cooperatives emerged successfully in France. Secondly, the chapter focuses on platform cooperatives in three domains, namely, meal delivery service, car-pooling, and energy. Finally, the chapter discusses how some identified factors could be considered as characteristics of a 'French touch' in terms of platform cooperativism.

In Chapter 13, Malte Höfner and Rainer Rosegger look at the peerto-peer accommodation sector in Austria. The chapter covers sharing economy business models, which range from market-based services to platform cooperatives and provides an overview of the sharing economy in Austria. Later, the authors critically analyse the impact of global sharing economy platforms such as Airbnb in the traditional hospitality sector and in the housing market in Austria. They highlight that despite the COVID-19 pandemic has demonstrated the general volatility of the tourism market sector, big market players such as Airbnb have been very quick to adapt to unstable markets in times of crisis. They suggest that peer-to-peer accommodation sustainable business models at the local level, such as Reposée or Schau auf's Land, could provide a good alternative to big platforms and be less disruptive to the traditional accommodation market sector.

In Chapter 14, Giulia Priora, Monica Postiglione, Stefano Valerio, Venere Sanna, and Chiara Bassetti, provide an overview of the development of the sharing economy in Italy, with a special focus on the main legal issues emerging from its consolidation. The authors also reflect on the main implications of the COVID-19 pandemic within the Italian 
sharing economy sector. The second part of the chapter focuses on analysing specific sharing economy activities, including mobility, accommodation, and food, among others. Furthermore, the chapter offers an account of the legislation related to the sharing economy in Italy and addresses a number of issues in regulating some of the sectors, e.g., accommodation. Finally, the chapter offers some policy recommendations, such as clearly defining the role and obligations of platforms and service providers.

Rodrigo Perez-Vega and Cristina Miguel, in Chapter 15, cover one of the traditional examples of the pure sharing economy: time banks in the UK context. First, the chapter introduces the main definitions and characteristics of timebanks and describes the different typologies, including person-to-person time banks, person-to-agency time banks, and organisation-to-organisation time banks. Later on, the authors discuss the benefits and limitations of time banks. In the last section, the chapter analyses the evolution of time banks in the UK and how the COVID-19 pandemic has fostered the development of new initiatives.

In Chapter 16, Agnieszka Lukasiewicz and Aleksandra Nadolska describe the development of the sharing economy in Poland-from the operation of big players, such as Uber or Airbnb, to smaller local initiatives. The authors also discuss some regulatory issues, such as labour law and competition, which often lead to conflicts between different stakeholders. In addition, the chapter also addresses different aspects of sharing economy initiatives embedded in the COVID-19 pandemic.

Finally, Eglantina Hysa and Alba Demneri Kruja, in Chapter 17, analyse the sharing economy initiatives within the agriculture and tourism sectors in Albania. The authors perform a SWOT (strengths, weaknesses, opportunities, and threats) analysis of the following Albanian sharing economy platforms: Agroquality, MIA (agriculture); and IntoAlbania, Innovation Map Albania, Team Albanians, and Softmogul (tourism). In the second part of the chapter, the authors recommend the use of the quadruple helix collaboration model in order to enhance the collaborative economy in Albania. At the end of the chapter, a discussion is emphasising the main ideas, as well as pointing out some limitations of the development of the sharing economy in Albania. 


\section{Summary}

Summing it up, the book provides an innovative and comprehensive presentation of the practices, as well as of the scientific outcomes related to the sharing economy, from the perspectives of different disciplines, including economics, management, organisational studies, sociology, public policy and administration, legal theory, computer, and information science as well as media and communication studies. The book comprehensively discusses the key positive and negative aspects of the sharing economy and best practices that can be disseminated internationally. It also provides new ideas regarding the relations of the sharing economy with the creative industries, solidarity and care sectors, and the COVID-19 pandemic. The book offers a multilevel perspective and combines topics important at the global, European, national, and local level. The book may illuminate the understanding of the future (sharing) economy models, as well as contribute to solving questions of better access to resources and sustainable innovation in the context of degrowth and growing inequalities within and between societies.

\section{References}

Avram, Gabriela, Jaz H. Choi, Stefano de Paoli, Ann Light, Peter Lyle, and Maurizio Teli. 2017. 'Collaborative Economies: From Sharing to Caring.' In Proceedings of the 8th International Conference on Communities and Technologies, edited by Douglas Schuler, Myriam Lewkowicz, Markus Rohde, and Ingrid Mulder, 305-7. New York, NY: ACM. https://doi.org/10.1145/ 3083671.3083712.

Bauwens, Michel, Nicolas Mendoza, and Franco, Iacomella. 2012. Synthetic Overview of the Collaborative Economy. Chiang Mai, Thailand: P2P Foundation.

Belk, Russell. 2007. 'Why Not Share Rather Than Own?' The Annals of the American Academy of Political and Social Science 611 (1): 126-40. https:// doi.org/10.1177/0002716206298483.

Belk, Russell. 2014. 'Sharing Versus Pseudo-Sharing in Web 2.0.' The Anthropologist 18 (1): 7-23. https://doi.org/10.1080/09720073.2014.11891518. 
Böcker, Lars, and Toon Meelen. 2017. 'Sharing for People, Planet or Profit? Analysing Motivations for Intended Sharing Economy Participation.' Environmental Innovation and Societal Transitions 23 (6): 28-39. https://doi.org/ 10.1016/j.eist.2016.09.004.

Botsman, Rachel, and Roo Rogers. 2010. What's Mine Is Yours: The Rise of Collaborative Consumption. New York, NY: Harper Business.

Bradley, Karin, and Daniel Pargman. 2017. 'The Sharing Economy as the Commons of the 21st Century.' Cambridge Journal of Regions, Economy and Society 10 (2): 231-47. https://doi.org/10.1093/cjres/rsx001.

Castells, Manuel, João Caraça, and Gustavo Cardoso. 2012. Aftermath: The Cultures of the Economic Crisis. Oxford: Oxford University Press.

Codagnone, Cristiano, Federico Biagi, and Fabienne Abadie. 2016. The Passions and the Interests: Unpacking the 'Sharing Economy'. Luxembourg: Publications Office of the European Union.

Eurobarometer. 2016. The Use of Collaborative Platforms: Flash Eurobarometer 438. Luxembourg: Publications Office of the European Union. Accessed May 20, 2021. https://europa.eu/eurobarometer/surveys/detail/2112.

Eurobarometer. 2018. Collaborative Economy in the EU: Flash Eurobarometer 467. Luxembourg: Publications Office of the European Union. Accessed May 20, 2021. https://europa.eu/eurobarometer/surveys/detail/2184.

Frenken, Koen, and Juliet Schor. 2019. 'Putting the Sharing Economy into Perspective.' In A Research Agenda for Sustainable Consumption Governance, edited by Oksana Mont, 121-35. Cheltenham, UK: Edward Elgar Publishing.

Frenken, Koen, Toon Meelen, Martijn Arets, and Peter Van de Glind. 2015. 'Smarter Regulation for the Sharing Economy.' The Guardian 20 (5). Accessed April 14, 2021. https://www.theguardian.com/science/political-sci ence/2015/may/20/smarter-regulation-for-the-sharing-economy.

Gansky, Lisa. 2010. The Mesh: Why the Future of Business Is Sharing. New York, NY: Portfolio.

Germann Molz, Jennie. 2014. 'Toward a Network Hospitality.' First Monday 19 (3). https://doi.org/10.5210/fm.v19i3.4824.

Habibi, Mohammad Reza, Andrea Kim, and Michel Laroche. 2016. 'From Sharing to Exchange: An Extended Framework of Dual Modes of Collaborative Nonownership Consumption.' Journal of the Association for Consumer Research 1 (2): 277-294. https://doi.org/10.1086/684685.

Hamari, Juho, Mimmi Sjöklint, and Antti Ukkonen. 2016. 'The Sharing Economy: Why People Participate in Collaborative Consumption.' Journal 
of the Association for Information Science and Technology 67 (9): 2047-59. https://doi.org/10.1002/asi.23552.

Howard, Billee. 2015. We-Commerce: How to Create, Collaborate, and Succeed in the Sharing Economy. New York, NY: Perigee Books.

ING. 2015. ING International Survey: Sharing Economy 2015: What's Mine Is Yours-for a Price: Rapid Growth Tipped for the Sharing Economy. Amsterdam: ING.

Klimczuk, Andrzej, Vida Česnuityte, and Gabriela Avram, eds. 2021. The Collaborative Economy in Action: European Perspectives. Limerick, Ireland: University of Limerick.

Lang, Bodo, Elsamari Botha, Jeandri Robertson, Joya A. Kemper, Rebecca Dolan, and Jan Kietzmann. 2020. 'How to Grow the Sharing Economy? Create Prosumers!.' Australasian Marketing Journal (AMJ) 28 (3): 58-66. https://doi.org/10.1016/j.ausmj.2020.06.012.

Lessig, Lawrence. 2008. Remix: Making Art and Commerce Thrive in the Hybrid Economy. New York, NY: Penguin Press.

Martos-Carrión, Esther, and Cristina Miguel. 2021. 'Sharing Economy: History, Definitions and Related Concepts.' In The Sharing Economy: Perspectives, Opportunities and Challenges, edited by Babak Taheri, Roya Rahimi, and Dimitrios Buhalis. Oxford: Goodfellow Publishers. Forthcoming.

Mosconi, Gaia, Agnieszka Lukasiewicz, and Gabriela Avram, eds. 2018. Member Countries Report on the Collaborative Economy: COST Action CA16121. Accessed May 20, 2021. http://sharingandcaring.eu/sites/default/ files/files/CountriesReport2018.pdf.

Owyang, Jeremiah, Christine Tran, and Chris Silva. 2013. The Collaborative Economy: Products, Services, and Market Relationships Have Changed as Sharing Startups Impact Business Models. To Avoid Disruption, Companies Must Adopt the Collaborative Economy Value Chain. San Mateo, CA: Altimeter Group. Accessed May 20, 2020. http://www.collaboriamo.org/ media/2014/04/collabecon-draft16-130531132802-phpapp02-2.pdf.

Schor, Juliet. 2014. 'Debating the Sharing Economy.' Accessed May 20, 2021. https://greattransition.org/publication/debating-the-sharing-economy.

Selloni, Daniela. 2017. CoDesign for Public-Interest Services. Cham: Springer International Publishing.

Stephany, Alex. 2015. Business of Sharing. Basingstoke, Hampshire: Palgrave Macmillan.

Timbro. 2018. Timbro Sharing Economy Index. Stockholm: Timbro. 
Open Access This chapter is licensed under the terms of the Creative Commons Attribution 4.0 International License (http://creativecommons.org/ licenses/by/4.0/), which permits use, sharing, adaptation, distribution and reproduction in any medium or format, as long as you give appropriate credit to the original author(s) and the source, provide a link to the Creative Commons license and indicate if changes were made.

The images or other third party material in this chapter are included in the chapter's Creative Commons license, unless indicated otherwise in a credit line to the material. If material is not included in the chapter's Creative Commons license and your intended use is not permitted by statutory regulation or exceeds the permitted use, you will need to obtain permission directly from the copyright holder.

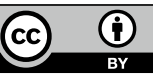

